Article

\title{
Eye-Gaze Control Technology as Early Intervention for a Non-Verbal Young Child with High Spinal Cord Injury: A Case Report ${ }^{\dagger}$
}

\author{
Helena Hemmingsson 1,2,*, Gunnar Ahlsten ${ }^{3}$, Helena Wandin ${ }^{4,5}$, Patrik Rytterström ${ }^{2}$ \\ and Maria Borgestig 2,6 \\ 1 Department of Special Education, Stockholm University, 11418 Stockholm, Sweden \\ 2 Department of Social and Welfare Studies, Linköping University, 58183 Norrköping, Sweden; \\ Patrik.Rytterstrom@liu.se (P.R.); maria.borgestig@liu.se (M.B.) \\ 3 Department of Women's and Children's Health, Uppsala University, 75236 Uppsala, Sweden; \\ gunnar.ahlsten@akademiska.se \\ 4 The Swedish National Center for Rett Syndrome \& Related Disorders, 83223 Frösön, Sweden; \\ helena.wandin@regionjh.se \\ 5 Department of Public Health and Caring Sciences, Uppsala University, 75122 Uppsala, Sweden \\ 6 Faculty of Medicine and Health, School of Health Sciences, Örebro University, 70281 Örebro, Sweden \\ * Correspondence: helena.hemmingsson@specped.su.se or Helena.Hemmingsson@liu.se; \\ Tel.: +46-072-148-2216 \\ + This paper is an extended version of our paper in Proceedings of AAATE2017 Congres, Sheffield, UK, \\ 13-14 September 2017; with permission from IOS Press.
}

Received: 12 December 2017; Accepted: 10 January 2018; Published: 16 January 2018

\begin{abstract}
Assistive technology (AT) can be used as early intervention in order to reduce activity limitations in play and communication. This longitudinal case study examines eye-gaze control technology as early intervention for a young child with high spinal cord injury without the ability to make sounds. The young child was followed by repeated measures concerning performance and communication from baseline at 9 months to 26 months, and finalized at 36 months by field observations in the home setting. The results showed eye-gaze performance and frequency of use of eye-gaze control technology increased over time. Goals set at 15 months concerning learning and using the AT; naming objects and interactions with family was successfully completed at 26 months. Communicative functions regarding obtaining objects and social interaction increased from unintentional actions to purposeful choices and interactions. At 36 months, the toddler was partly independent in eye gazing, used all activities provided, and made independent choices. In conclusion, the results show that a 9-month-old child with profound motor disabilities can benefit from eye-gaze control technology in order to gradually perform activities, socially interact with family members, and make choices.
\end{abstract}

Keywords: tetraplegia; gaze-based assistive technology; communication; goal directed activities; self-help devices

\section{Introduction}

This paper is an extended version of the publication done in 2017 for the Association for the Advancements of Assistive Technology in Europe (AAATE) conference in United Kingdom. Additional information and figures have been added and discussed [1]. The young child has been involved in earlier research regarding 10 children with severe physical impairments without speaking abilities in which eye-gaze performance and computer usage were reported on a group level $[2,3]$. This case 
report focuses on an individual child's learning and the performance of eye gaze control technology and video observations over time. In addition, field observation of the individual child is included.

Non-verbal toddlers with profound motor impairments may have difficulties catching up in important developmental areas due to difficulties in initiating actions, exploring activities, and communicating with parents and others. For these children, there is a delay between what they are able to do and what is expected for their age [4]. In order to create opportunities for actions and promote child development $[4,5]$ eye-gaze control technology might be a promising early intervention. Eye-gaze control technology allows the child to use the movements of their eyes to operate a computer. The system involves a camera in the computer that tracks eye movements, which in turn controls the cursor on the screen [6,7]. Accordingly, the device has the potential to provide opportunities for children with severe motor impairments without speech to initiate and explore self-directed actions and activities through eye gaze and use the screen to communicate with parents and siblings.

Previous studies in eye-gaze control technology for children with disabilities are sparse [7], but recently published research shows that children with severe motor disabilities without speech can learn to use eye-gaze control technology and have positive effects from this [2,3,8]. Karlsson et al. [6], in a systematic literature review on the effectiveness of eye-gaze control technology for communication, only found two applicable studies and argued that evidence is required to guide the selection of appropriate potential users, as implementing eye-gaze control technology is expensive and time-consuming. Accordingly, there is evidence that eye-gaze control technology benefits children with profound motor impairments. A question of clinical importance that still remains to be answered is at what age is it appropriate to introduce gaze based AT as early intervention. As a first step, this case report follows a toddler with a high spinal cord injury and no speech ability from 9 months to 36 months with the aim to investigate eye-gaze control technology as an opportunity in early intervention for the performance of activities and communication.

\section{Materials and Methods}

This study has a longitudinal design and follows the Care guidelines for clinical case reports [9]. Data collection started on October 2012 and was finished on December 2014.

\subsection{Ethical Considerations}

Parents to the toddler gave their informed consent for inclusion before they participated in the study. The study was conducted in accordance with the Declaration of Helsinki, and ethical approval was granted by the Regional ethical review board in Uppsala, Sweden (2010/316). The name used in this article referring to the young child is a pseudonym.

\subsection{Patient Information and Diagnostic Assessments}

Lucas was born at term in a normal delivery, and his first days in life were normal. He fell ill about one week after birth with signs of a serious infection, and he was diagnosed with septicemia and meningitis due to an acute bacterial infection. He was treated with antibiotics and improved, but later on had recurrent episodes during the first two months with serious and unclear symptoms. Several CT and MRI scans of the brain were performed and proved to be normal. Around the age of three months, his conditions worsened with breathing problems and signs of paralysis in both his trunk and all extremities. Neuroradiological examinations now showed clear signs of an osteomyelitis in the bone structures of the skull base and cervical vertebras 1 and 2 . There was a destruction of bone in this area leading to an instability of the neck. The neurological symptoms were due to a compression of the brain stem and proximal parts of medulla spinalis. The neck region was stabilized by a surgical procedure. Lucas has a severe motor impairment-tetraplegia—and his breathing is supported during sleep by a non-invasive ventilator (BIPAP), but he breathes normally while awake. His hearing and vision is normal as well as his eye movements and facial muscles, but he was not able to make sounds. The case described above is extremely uncommon, and the literature does not provide any evidence 
about the further development. Lucas stayed at the hospital most of the time during his first 10 months and afterward moved home to his parents and sibling. A follow-up MRI later showed new signs of compression in the craniocervical junction, and a new operation was performed at the age of 2 years and 10 months. The situation has since this been stable.

\subsection{Interventions}

Figure 1 shows a timeline of interventions and data collections.

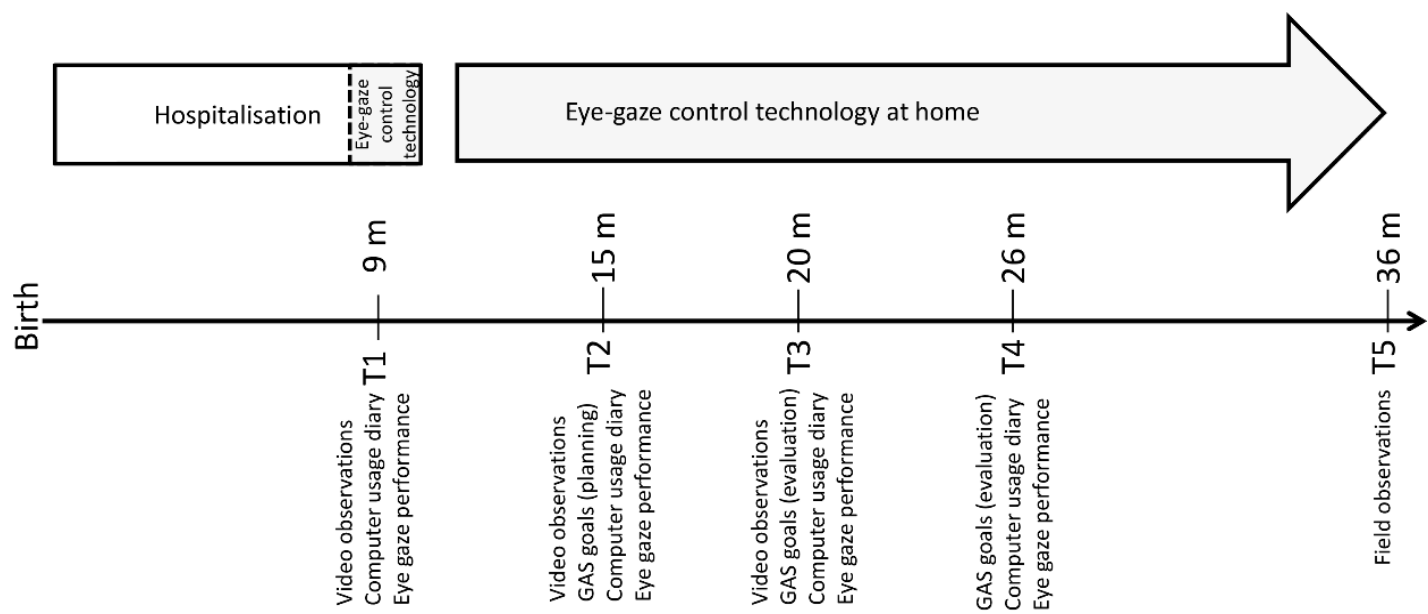

Figure 1. Timeline with data collection at T1-T5. The first attempts to use eye-gaze control technology occurred during hospitalization.

Before moving home, a referral was sent to a communication center to assess if eye-gaze control technology could provide him with opportunities to be active, communicate, and explore the world. The child started to try and learn controlling the computer with eye gaze at nine months of age during sessions at the ward. These sessions indicated that the child had a good ability to focus the gaze on small objects on the screen that seemed to interest him; however, according to the team and his mother's estimation at that time, he did not understand that he moved the cursor with his gaze.

After moving home, the eye-gaze control technology intervention was introduced. Lucas was provided with eye-gaze control technology at home and supported by a special communication team at the age of 15 months. The eye-gaze control technology was a C12 (12 ${ }^{\prime \prime}$ screen) from Tobii Technology [10], which is a one-piece unit with an eye camera incorporated in the computer. The software programs included in the eye-gaze control technology were Communicator with speech output [10] and Look to Learn [11]. These consist of 40 games to learn cause and effect and choice making skills. The specialists at the communication team, together with parents, built up dynamic pages in Communicator with play activities, as well as pages with music, fairy tales, and pictures for early communication. Altogether, these pages were comprised of approximately 50 pictures (see Figure 2 for a page with a play activity. The parents learned how to support the child in using the eye-gaze control technology and were recommended to give the child the opportunity to use the eye-gaze control technology on a daily basis and as often as he wanted. The services from the multi-professional team were based upon research-based key elements (increasing parents' knowledge about eye-gaze technology, collaboration among key persons, goal setting and considering the child's preferences for usage) and are well-described elsewhere (for details, see Borgestig, Sandqvist, Ahlsten, Falkmer, and Hemmingsson [2]). 


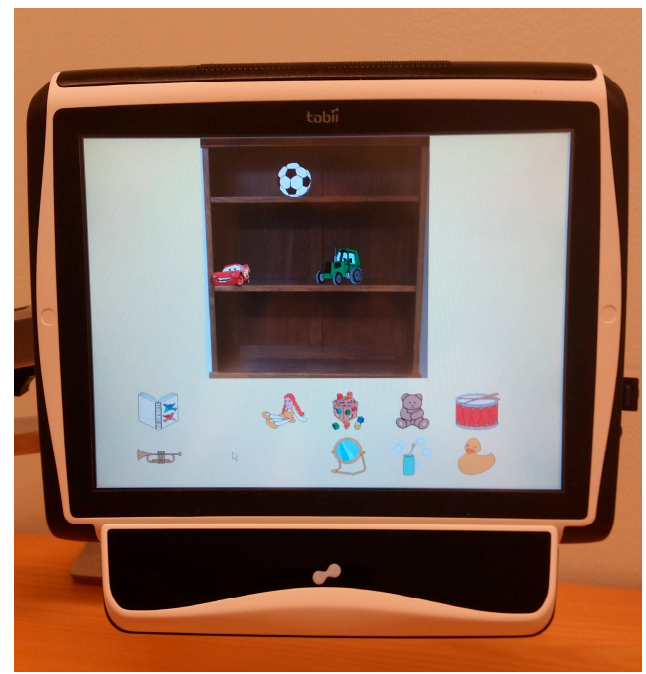

Figure 2. Example of a page with a play activity in the eye-gaze control technology. When fixating ones eye gaze on a toy, it moves to the shelf.

\subsection{Assessments}

Figure 1 shows time points for data collection.

Eye-gaze performance (accuracy in eye gazing and time on task) was measured at T1-T4 with the Aim test in Compass 2.0 Software for Access Assessment [11]. Psychometric properties of the Aim test showed good results [12,13].

The Goal Attainment Scale (GAS) [14] was used to measure goal attainment in meaningful computer activities at T2-T4. Computer activities and goals were cooperatively decided by parents and professionals. When predefining and grading the goals at T2, the current level of eye-gaze technology usage was set to -2 on the five-point scale from -2 (much less than expected) to +2 (much more than expected) with 0 (expected), +1 (more than expected), and +2 as successful levels. GAS has shown good responsiveness in detecting clinically relevant change $[15,16]$.

Computer usage diaries [6] assessed the use of eye-gaze control technology in the home setting at four time points T1-T4. Through direct observation, the parents reported the child's daily computer usage in number of days/week, minutes/day, and number and type of performed activities (activity repertoire).

The child's communication concerning the communicative functions of "obtaining things" and "social interaction" when using eye-gaze control technology was rated based on the Communication Matrix intended for early communication behaviors corresponding to the age of 0-24 months [17]. The Communication Matrix categorizes communicative behavior in different areas in seven levels from the earliest level—pre-intentional behavior to the highest level—using symbols and language. From video clip observations at T1-T3 $(n=6)$, two of the authors independently assessed the level of behavior of each video clip (Levels I-VII). Observer 1 was blind to time point and had no previous knowledge of the child (interrater reliability was 74-96\%).

At the age of 36 months, Lucas was observed twice in the home setting by a researcher when using eye-gaze control technology. The researcher wrote detailed field notes during the observations. The observations of Lucas' use of the eye-gaze control technology lasted for about $30 \mathrm{~min}$ on both occasions and focused on independency in computer use, communication, and social interaction.

\section{Results and Discussion}

Figure 3 shows that Lucas' eye-gaze performance (accuracy in eye gazing and time on task) measured with Compass 2.0 increased over time. His precision in selecting targets (accuracy) improved 
fast, and already at T2 he reached almost 100\% in accuracy. Time on task improved over time and decreased from $8 \mathrm{~s}$ at T1, to $4 \mathrm{~s}$ at T2, and then to $2 \mathrm{~s}$ at T3 and T4.

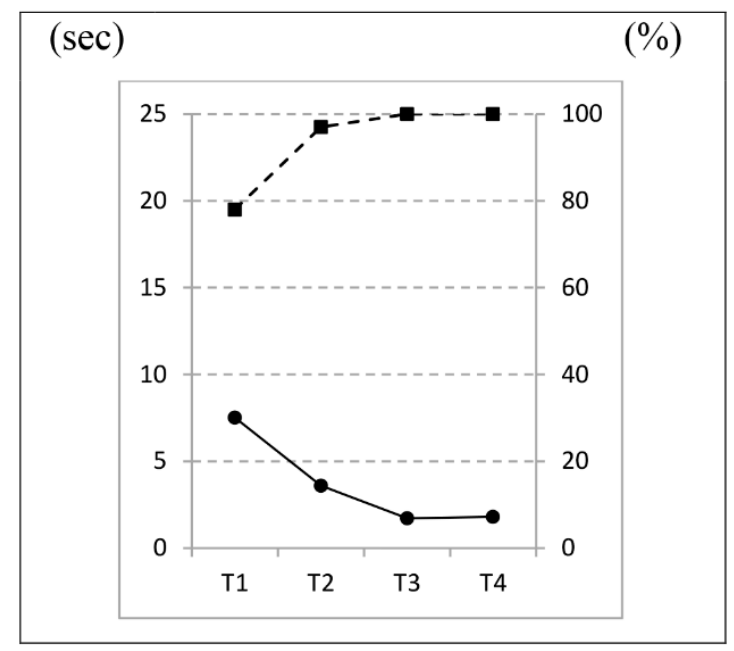

Figure 3. Eye-gaze performance measured at T1-T4. The child's age was 9 months at T1, 15 months at T2, 20 months at T3, and 26 months at T4. Dotted line: Accuracy (\%), Continuous line: Time on task, in seconds (median value).

The goals, cooperatively set by parents and professionals and measured by GAS were evaluated over time. All four of the following predefined goals were successfully attained at T4: (a) making finds among all pages in the eye-gaze control technology (GAS Level +1); (b) having a regular computer usage of five days a week (GAS Level 0); (c) interacting spontaneously with parents and sibling during play activities with eye-gaze control technology (GAS Level +2); and (d) naming objects by eye pointing, while sometimes in need of verbal guidance (GAS Level 0). Analysis of the computer diary demonstrated that the frequency of use in everyday life increased over time (T1-T4) from 43 to $77 \%$ of days/week and that the minutes of use per day increased from 25-38 min/user day. At the age of 26 months (T4), he used all categories of activities available (e.g., photos, play activities, music, and fairy tales).

The results regarding communicative functions, as measured by the Communication Matrix, showed that the ability to obtain things using eye-gaze control technology emerged over time from unintentional choices of screen selections with eye gaze at the age of 9 months (baseline, Level II) to intentional choices of up to 10 objects offered on screen at 16 months (T2, Level III unconventional communication). This increased to 30 objects on screen at the age of 21 months (Level III) (T3). In addition to this, he learned to request more from the partner's action by pointing with eye gaze to a specific picture of the desired activity he wanted to continue with at T3 (Level IV, conventional communication).

Social interaction emerged from unintentionally attracting the partner's attention by consistently showing interest and looking at the screen (baseline, Level II) in order to intentionally request the partner's attention and responding with smiling and smacking during eye gaze-computer interaction (T2, Level III). In addition to this, he also intentionally directed the partner's attention to his actions on screen by looking back and forth between the objects on the screen and the partner (T3, Level IV).

The field observations in the home setting showed that, at the age of 36 months, Lucas was partly independent in the performance with eye-gaze control technology but still now and then needed his mother's guidance and support for the actions. For example, the mother pointed on the computer screen to show where to fixate with the gaze to change back to a previous page, or the mother commented on what Lucas did and what happened based on his actions. Lucas was observed to make independent choices with eye gaze as well as respond to his mother's suggestions of activities. He also 
showed his own preferences beyond his mother's recommendations. For example, with expressions of delight mixed with terror, he repeatedly chose to start a scary fairy tale even though his mother warned him and suggested other fairy tales.

The results of the present case report demonstrate that a child with profound motor impairments can as early as 9 months start using eye-gaze control technology in order to gradually perform play activities, make choices, and socially interact with parents. Hence, for young children with tetraplegia, eye-gaze control technology can be a tool for play and learning to promote development. This case report will inform practice about AT's usefulness for non-verbal children without the ability to voluntarily control any body part except the eyes. In the future, these promising results need to be tested in a controlled study following children's learning and development when advancing from an infant to preschool age. It is important to bear in mind that this case study provides an example and that, when considering the age of the child, it might be appropriate to start using eye-gaze control technology even earlier than this study reports. Future research is needed to provide precise recommendations as to when it is most efficient to start using eye-gaze control technology for promoting learning and development in children with profound motor impairments without the ability to make sounds.

It is possible the positive results in this study are related to the type of intervention provided. Earlier research has shown that involving key persons such as parents and providing them with the knowledge and skills needed is in the long run essential to a sustained use of assistive technology [18,19]. The parents in this study received education on eye-gaze control technology and on how to support their child. It was recommended to them that they give their child opportunities to use the eye-gaze control technology on a daily basis and as often as the child wanted. The rehabilitation team collaborated with them over time to set goals and to find a broad range of doable computer activities with respect to the age of the child. Thus, results from research that cannot provide opportunities for the same length or intensity of the training might not be comparable.

The strength of the study is that the child's development in gaze-based usage was repeatedly followed over time by different measurements. However, field observations were only performed at the end of the study, resulting in limited material for describing children's use in everyday life, as well as their independence in computer use and social interaction with family at the earliest ages.

In conclusion, the results indicate that eye-gaze control technology can be a promising tool used for early intervention to promote young children's development and learning.

Acknowledgments: We offer special thanks to the family who participated in this study. This research was founded by the Swedish research council, 521-2012-3057.

Author Contributions: Helena Hemmingsson and Maria Borgestig designed the study. Maria Borgestig and Patrik Rytterström performed the measurements and data collection. In addition, Gunnar Ahlsten collected and was responsible for medical information concerning the patient information and diagnostic assessments. Maria Borgestig and Helena Wandin performed the data analysis in relation to the measurements. Helena Hemmingsson and Patrik Rytterström analyzed the field observations. Helena Hemmingsson was mainly responsible for writing the paper in cooperation with Maria Borgestig and Gunnar Ahlsten that contributed with specific parts. Patrik Rytterström and Helena Wandin was also active in writing by providing comments and suggestions during the process.

Conflicts of Interest: The authors declare no conflict of interest.

\section{References}

1. Hemmingsson, H.; Borgestig, M. Gaze-Based Assistive Technology for a Toddler with Tetraplegia without Speech. In Harnessessing the Power of Technology to Improve Lives, Proceedings of the 14th Conference of the Association for the Advancement of Assistive Technology in Europe (AAATE 2017), Sheffield, UK, 13-14 September 2017; Studies in Health Technology and Informatics; Peter, C., de Witte, L., Eds.; IOS Press BV: Amsterdam, The Netherlands, 2017; Volume 242, pp. 1109-1112. 
2. Borgestig, M.; Sandqvist, J.; Ahlsten, G.; Falkmer, T.; Hemmingsson, H. Gaze-based assistive technology in daily activities in children with severe physical impairments-An intervention study. Dev. Neurorehabilit. 2017, 20, 129-141. [CrossRef] [PubMed]

3. Borgestig, M.; Sandqvist, J.; Parsons, R.; Falkmer, T.; Hemmingsson, H. Eye gaze performance for children with severe physical impairments using gaze-based assistive technology-A longitudinal study. Assist. Technol. 2016, 28, 93-102. [CrossRef] [PubMed]

4. Bruder, M.B. Early childhood intervention: A promise to children and families for their future. Except. Child. 2010, 76, 339-355. [CrossRef]

5. Guralnick, M.J. Why Early Intervention Works: A Systems Perspective. Infants Young Child. 2011, $24,6-28$. [CrossRef] [PubMed]

6. Karlsson, P.; Allsop, A.; Dee-Price, B.-J.; Wallen, M. Eye-gaze control technology for children, adolescents and adults with cerebral palsy with significant physical disability: Findings from a systematic review. Dev. Neurorehabilit. 2017, 1-9. [CrossRef] [PubMed]

7. Majaranta, P.; Aoki, H.; Donegan, M.; Hansen, D.W.; Hansen, J.P.; Hyrskykari, A.; Räiha, K. Gaze Interaction and Applications of Eye Tracking: Advances in Assistive Technologies; Medical Information Science Reference: Hershey, PA, USA, 2012.

8. Rytterström, P.; Borgestig, M.; Hemmingsson, H. Teachers' experiences of using eye gaze-controlled computers for pupils with severe motor impairments and without speech. Eur. J. Spec. Needs Educ. 2016, 31, 506-519. [CrossRef]

9. Gagnier, J.J.; Kienle, G.; Altman, D.G.; Moher, D.; Sox, H.; Riley, D.; The CARE Group. The CARE guidelines: Consensus-based clinical case report guideline development. J. Clin. Epidemiol. 2014, 67, 46-51. [CrossRef] [PubMed]

10. Assistive Technology Products (AAC). Tobii Technology. 2013. Available online: http://www.tobii.com/en/ assistive-technology/global/products/old-or-discontinued-products/ (accessed on 22 December 2014).

11. Smartbox. Smart Box Assistive Technology. 2017. Available online: https://thinksmartbox.com/ (accessed on 15 October 2017).

12. Koester, H.; LoPresti, E.; Simpson, R. Further validation of the "aim" test for assessing a user's mouse skills. In Proceedings of the RESNA Annual Conference, Toronto, ON, Canada, 5-8 June 2011; RESNA Press: Arlington, VA, USA, 2011.

13. Koester, H.; Simpson, R.C.; Spaeth, D.; LoPresti, E. Reliability and validity of Compass software for access assessment. In Proceedings of the RESNA Annual Conference, Phoenix, AZ, USA, 15-19 June 2007; RESNA Press: Arlington, VA, USA, 2007.

14. Kiresuk, T.J.; Smith, A.; Cardillo, J.E. Goal Attainment Scaling: Applications, Theory, and Measurement; Lawrence Erlbaum: Hillsdale, NJ, USA, 1994.

15. Sakzewski, L.; Boyd, R.; Ziviani, J. Clinimetric properties of participation measures for 5-to 13-year-old children with cerebral palsy: A systematic review. Dev. Med. Child Neurol. 2007, 49, 232-240. [CrossRef] [PubMed]

16. Steenbeek, D.; Gorter, J.W.; Ketelaar, M.; Galama, K.; Lindeman, E. Responsiveness of goal attainment scaling in comparison to two standardized measures in outcome evaluation of children with cerebral palsy. Clin. Rehabilit. 2011, 25, 1128-1139. [CrossRef] [PubMed]

17. Rowland, C.; Fried-Oken, M. Communication Matrix: A clinical and research assessment tool targeting children with severe communication disorders. J. Pediatr. Rehabilit. Med. 2010, 3, 319-329. [CrossRef]

18. Baxter, S.; Enderby, P.; Evans, P.; Judge, S. Barriers and facilitators to the use of high-technology augmentative and alternative communication devices: A systematic review and qualitative synthesis. Int. J. Lang. Commun. Disord. 2012, 47, 115-129. [CrossRef] [PubMed]

19. Van Niekerk, K.; Tönsing, K. Eye-gaze technology: A South African perspective. Disabil. Rehabilit. Assist. Technol. 2015, 10, 340-346. [CrossRef] [PubMed]

(c) 2018 by the authors. Licensee MDPI, Basel, Switzerland. This article is an open access article distributed under the terms and conditions of the Creative Commons Attribution (CC BY) license (http://creativecommons.org/licenses/by/4.0/). 